\title{
Intelligent CPAP systems: clinical experience
}

\author{
$\mathrm{H}$ Teschler, M Berthon-Jones
}

Nasal continuous positive airway pressure (CPAP) remains the treatment of choice for obstructive sleep apnoea (OSA) syndrome. It is believed to work by pneumatically splinting the upper airway. ${ }^{12}$ As the pressure is gradually increased the subject passes through a spectrum of gradually decreasing severity of obstruction. ${ }^{34}$ Frank obstructive apnoeas, hypopnoeas, and desaturation first disappear, then $2-4 \mathrm{~cm} \mathrm{H}_{2} \mathrm{O}$ higher snoring and most respiratory arousals disappear, leaving only silent inspiratory airflow limitation associated with high respiratory work. This occurs at an average pressure of $8 \mathrm{~cm} \mathrm{H}_{2} \mathrm{O}$. A further increase of $2 \mathrm{~cm} \mathrm{H}_{2} \mathrm{O}$ produces a $75 \%$ reduction in respiratory work and normal breathing. A higher pressure is required to prevent apnoeas in REM sleep and in the supine position, and the lowest pressure is required in slow wave sleep in the lateral position. ${ }^{5}$

Although nasal CPAP has no serious side effects in subjects with uncomplicated sleep apnoea syndrome, there are several minor side effects that reduce patient compliance and quality of life. These are chiefly pressure related, the most frequent being dryness, burning, and congestion of the nasal mucosa, discomfort exhaling against the pressure, chest wall discomfort, middle ear discomfort, mask and machine noise, conjunctivitis from leaks into the eyes, and air swallowing. ${ }^{6-11}$ The first goal of treatment initiation is therefore a "pressure titration" to find a pressure that makes a reasonable trade-off between increasing effectiveness at eliminating respiratory related events and avoiding unpleasant side effects. ${ }^{12}$ Current practice is to perform the titration in the laboratory with full polysomnography, gradually increasing the pressure through the spectrum described above, in all body positions and sleep stages. ${ }^{13}$ This is skilled, tedious, and expensive work. Furthermore, it is controversial whether the pressure determined in this way will still be correct in a month or a year's time after resolution of upper airway trauma and sleep deprivation, or with cold dry weather, seasonal allergy, or ingestion of alcohol. ${ }^{56111415}$

Auto-titrating systems provide a method for determining a single fixed pressure, suitable for subsequent long term home treatment with a conventional CPAP device. Their goal is to avoid the cost and labour of a manual titration. Conversely, auto-adjusting systems are intended for long term home treatment. Their goal is to improve effectiveness and/or reduce side effects by ensuring that the instantaneous pressure is always close to optimal. ${ }^{12}{ }^{16}$ This paper will concentrate on experience at the Ruhrlandklinik using AutoSet Clinical, an in-laboratory auto-titrating system, and Auto-
Set Portable which can be used either as an auto-titrating or an auto-adjusting system (ResMed, Sydney).

\section{AutoSet algorithm: elimination of silent inspiratory airflow limitation}

Montserrat and colleagues ${ }^{4}$ and Condos et $a l^{\beta}$ have shown that reducing the CPAP pressure by as little as $2 \mathrm{~cm} \mathrm{H}_{2} \mathrm{O}$ below the optimal level produces silent inspiratory airflow limitation with partial collapse of the upper airway and typically a fourfold increase in oesophageal pressure swings. It seems reasonable to assume that the cost in side effects of increasing the titration pressure by $2 \mathrm{~cm} \mathrm{H}_{2} \mathrm{O}$ will be outweighed by the benefit of the $75 \%$ reduction in work of breathing. The AutoSet system therefore titrates not only to eliminate apnoeas and snoring, but also further increases the mask pressure in the presence of flattening of the inspiratory flow-time curve, suggestive of unresolved silent inspiratory airflow limitation. ${ }^{17}$ Snoring causes the pressure to increase at up to $1 \mathrm{~cm} \mathrm{H}_{2} \mathrm{O}$ per breath so that these events are eliminated rapidly. Flattening of the flow-time curve causes a slower approach to the final pressure over the next several minutes. When there is no snoring or flattening the pressure gradually decreases with a time constant of 20 minutes. Thus, in general the system acts preemptively to increase the pressure before obstructive apnoeas occur. In addition, the AutoSet Clinical and Portable systems, which are intended for use on the first treatment night, detect apnoeas, classify them into those with an open airway and those where the airway is closed, and optionally increase the mask pressure in the presence of closed airway apnoeas. Hypopnoeas are ignored unless there is associated evidence of snoring or silent airflow limitation.

AutoSet then recommends a single fixed pressure (AutoSet titration pressure) suitable for subsequent long term home treatment with conventional fixed pressure nasal CPAP. ${ }^{17}{ }^{18}$ The algorithm firstly excludes those parts of the night where the measured leak exceeds $0.4 \mathrm{l} / \mathrm{s}$ (on average, $10 \%$ of a supervised night and $15 \%$ of an unsupervised night), and then takes the pressure that is exceeded only $5 \%$ of the time during the remainder of the study. ${ }^{12}{ }^{19}$

\section{In-laboratory auto-titration}

The elimination of flow limitation as the end point of titration is still controversial. ${ }^{3412}$ The aim of one acute study was to test, in previously untreated subjects with OSA, how well the AutoSet algorithm actually treated the patient on the titration night. Did it generate sufficient pressure to largely eliminate obstructive respiratory arousals but not so much 


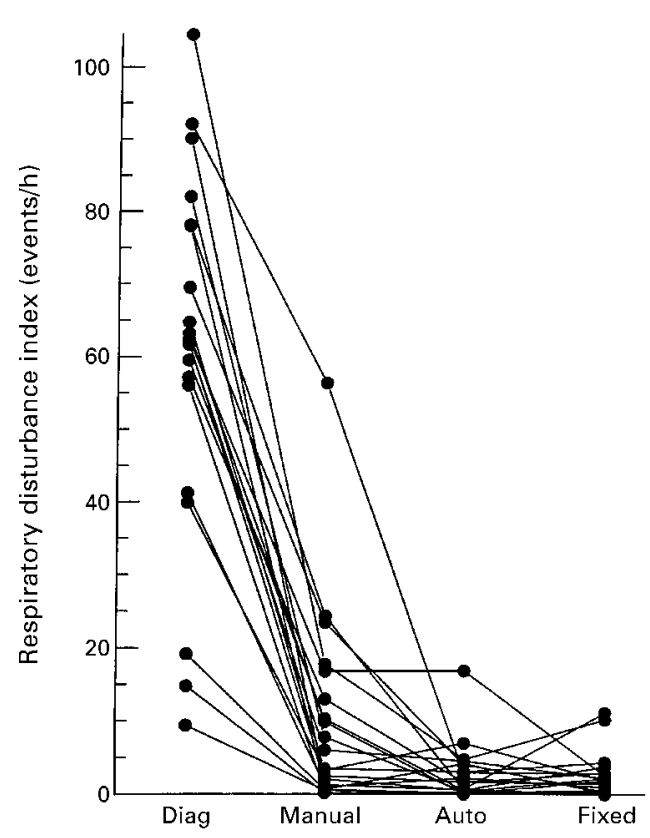

Figure 1 Effect of nasal CPAP on respiratory disturbance index. Diag = diagnostic night without CPAP; manual = manual titration night; auto $=$ AutoSet automatic titration night; fixed $=$ conventional fixed pressure treatment at pressure recommended from AutoSet night.

pressure as to interfere with sleep architecture or generate central respiratory arousals? ${ }^{17}$ Another aim was to test sleep and breathing on a second night using conventional CPAP at the AutoSet titration pressure determined on the first night. ${ }^{17}$

Twenty subjects were studied over four nights: a diagnostic night, an AutoSet titration night, a manual titration night, and a fixed pressure night at the previously determined AutoSet titration pressure. (An additional subject was eliminated from the study because it was not possible to obtain an adequate seal between mask and face.) The results are as shown in figs 1 and 2 and table 1 . As expected, manual, AutoSet, and fixed nights all produced a large decrease in the number of obstructive events, no important increase in the number of central events, and a great improvement in the sleep architecture. The total arousal index using ASDA microarousal criteria was comparable with the value reported by Mathur et $a l^{20}$ in age matched normal subjects on their first night in the laboratory. These results demonstrate that, in

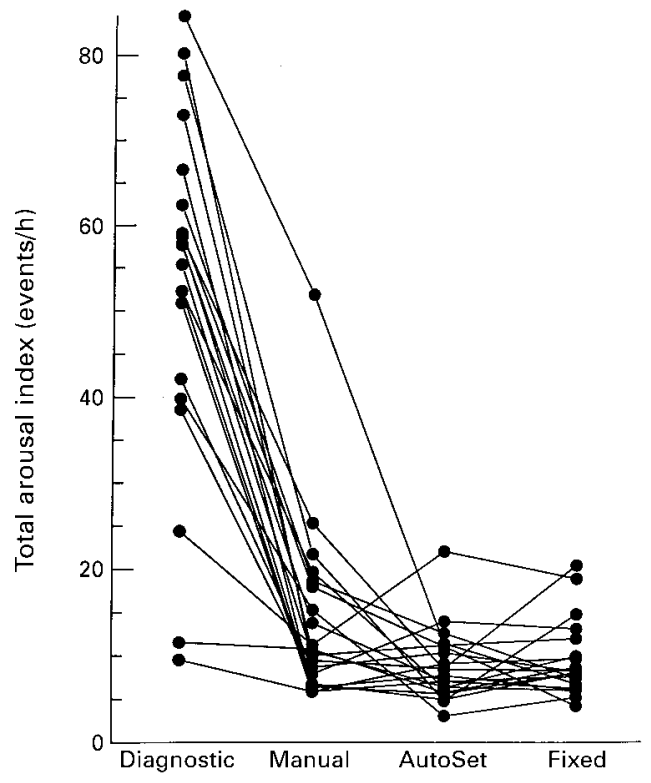

Figure 2 Effect of nasal CPAP on total arousal index. Diagnostic = diagnostic night without CPAP; manual = manual titration night; auto $=$ AutoSet automatic titration night; fixed $=$ conventional fixed pressure treatment at pressure recommended from AutoSet night.

previously untreated subjects, AutoSet increases pressure sufficiently to largely eliminate obstructive events without generating central events or disturbing sleep architecture, and that sleep and breathing remain corrected on the fixed pressure night at the AutoSet recommended titration pressure.

To confirm that these subjects were indeed adequately treated at home on the chosen fixed pressures, subjects were tested at home on fixed pressure using the Nellcor EdenTrace. ${ }^{18}$ The apnoea + hypopnoea index (AHI) at home was $4.3(0.6)$ at three months and $3.6(0.5)$ at eight months (compared with 60.3 (5.7) untreated and $2.5(0.7)$ on the first treatment night using polysomnography). The small difference between the AHI on the first treatment night and at three and eight months is probably due to a small difference between polysomnographic and EdenTrace scoring criteria - the former but not the latter required a $4 \%$ desaturation.

One of us (HT) has since used AutoSet Clinical routinely in 1000 patients with uncomplicated OSA (see below for exclusions).

Table 1 Mean (SD) respiratory, sleep stage, and arousal results

\begin{tabular}{lcccc}
\hline & Diagnostic & Manual & AutoSet & Fixed \\
\hline Apnoea + hypopnoea index (events/h) & $60.3(5.7)$ & $10.1(3.0)$ & $2.8(0.9) \mathrm{m}^{\star \star}$ & $2.5(0.7) \mathrm{d}^{\star \star \star}$ \\
Apnoea duration (s) & $34.7(2.1)$ & $22.4(1.5)$ & $16.1(1.9) \mathrm{m}^{\star}$ & $16.1(2.2) \mathrm{d}^{\star \star \star}$ \\
Mean nadir saturation (\%) & $70.9(2.2)$ & $84.8(1.4)$ & $90.4(0.8) \mathrm{m}^{\star \star}$ & $90.0(0.9) \mathrm{d}^{\star \star \star}$ \\
Total sleep time (min) & $357(4.6)$ & $366(4.3)$ & $344(5.8) \mathrm{m}^{\star \star \star}$ & $358(4.3) \mathrm{a}^{\star \star}$ \\
Stage 1 sleep (\%) & $28.6(4.0)$ & $14.7(1.9)$ & $13.8(1.6)$ & $12.9(1.5) \mathrm{d}^{\star \star}$ \\
Stage 2 sleep (\%) & $46.9(2.9)$ & $25.8(2.4)$ & $26.0(2.3)$ & $29.0(2.4) \mathrm{d}^{\star \star \star}$ \\
Slow wave sleep (\%) & $8.1(2.2)$ & $30.5(4.2)$ & $29.8(3.1)$ & $32.5(2.9) \mathrm{d}^{\star \star \star}$ \\
REM sleep (\%) & $10.3(1.6)$ & $22.9(1.5)$ & $21.0(1.3)$ & $20.4(1.8) \mathrm{d}^{\star \star \star}$ \\
Respiratory arousal index (events/h) & $49.6(4.9)$ & $7.9(2.4)$ & $1.5(0.6) \mathrm{m}^{\star \star}$ & $1.3(0.4) \mathrm{d}^{\star \star \star}$ \\
Non-respiratory arousal index (events/h) & $3.1(0.6)$ & $6.3(0.7)$ & $7.4(0.8)$ & $8.2(1.0) \mathrm{d}^{\star \star \star}$
\end{tabular}

Diagnostic = diagnostic study without CPAP; manual = manual titration night; AutoSet = AutoSet automatic titration night; fixed $=$ conventional fixed pressure treatment at pressure recommended from AutoSet night

$d^{\star}, d^{\star \star}, d^{\star \star \star}$, significantly different from diagnostic ( $<<0.05, p<0.01, p<0.001$, respectively); $a^{\star}, a^{\star \star}, a^{\star \star \star}$, significantly different from AutoSet $\left(\mathrm{p}<0.05, \mathrm{p}<0.01, \mathrm{p}<0.001\right.$, respectively); $\mathrm{m}^{\star}, \mathrm{m}^{\star \star}, \mathrm{m}^{\star \star \star}$, significantly different from manual titration $(\mathrm{p}<0.05$, $\mathrm{p}<0.01, \mathrm{p}<0.001$, respectively). 
Subjects were habituated to the device for 20-30 minutes at $10 \mathrm{~cm} \mathrm{H}_{2} \mathrm{O}$ pressure in the daytime prior to the study, with meticulous attention to mask fitting, to training the subject to obtain a good seal, and to ensuring that the technicians were familiar with the device. A satisfactory study was defined as one in which there were $<5$ apnoeas per hour, $<15 \%$ of the night with a leak of more than $0.4 \mathrm{l} / \mathrm{s}$, the haemoglobin oxygen saturation exceeded $90 \%$ for at least $95 \%$ of the study, and the subject was subjectively able to sleep with the pressure. It was not possible to derive a satisfactory titration pressure in 38 of 1000 patients. In 27 patients this was due to mouth breathing or severe leaking, in six patients because the nasal airway was not patent, and in five subjects the pressure appeared to be unnecessarily high due to incorrect calibration of the device. A satisfactory result was obtained the next night in these subjects. No serious side effects (bradyarrhythmias, cardiac failure, pneumothorax, sustained arterial oxygen desaturation) were observed.

We conclude that the AutoSet algorithms provide very good treatment of OSA on the first night, that the AutoSet titration pressure yields satisfactory sleep and breathing on the first night of fixed pressure treatment, and that with 20 minutes of meticulous patient preparation a suitable single titration pressure can be obtained in $96 \%$ of studies.

\section{Home auto-adjusting CPAP therapy}

Peak CPAP pressure is usually required in the supine position ${ }^{5}$ and many subjects have frank OSA only in REM sleep. ${ }^{21}$ However, the relationship between sleep stage and upper airway resistance syndrome remains to be determined, and it is our impression that to eliminate inspiratory airflow limitation the highest pressures are required in stage 1 sleep and the lowest pressures in slow wave sleep. Certainly, no pressure at all is required in the awake state while waiting to go to sleep. Therefore a device which adjusts the pressure on a minute-byminute basis has the potential to reduce mean pressure delivery and pressure related side effects but still guarantee to meet peak pressure demand. The goal of an auto-adjusting device is to improve the trade-off between side effects and effectiveness, with a view to improving compliance and quality of life. ${ }^{12}$

Ten subjects with uncomplicated OSA were tested in a medium term double blind crossover study designed to compare sleep, breathing, and delivered pressure using AutoSet Portable versus manually titrated fixed pressure CPAP. ${ }^{19}$ Subjects were manually titrated in the laboratory and then treated at home with AutoSet Portable for two months in auto mode, followed by two months in conventional fixed pressure mode at the manually determined pressure, or vice versa in random order.

The device was downloaded at the patient's home at regular intervals to obtain pressure, leak, and usage information. Compliance exceeded $98 \%$ and mean (SE) daily usage was very high in both modes (auto $6.3(0.4)$ versus fixed $6.1(0.5) \mathrm{h} /$ day, NS). Median pressure in auto mode was 77 (4)\% of the manually determined fixed pressure, with individual subjects showing a reduction to as little as $37 \%$ of the manually determined fixed pressure. Percentage of time with severe leaking $(>0.41 / \mathrm{s})$ was small and very similar in both modes (auto 10 (3) \%, fixed 13 (3)\%, NS). There was some variability in auto-titration pressure from night to night. The within-subject standard deviation for the 95th centile pressure was $1.07 \mathrm{~cm} \mathrm{H}_{2} \mathrm{O}$ giving a $95 \%$ confidence interval of \pm 2.08 $\mathrm{cm} \mathrm{H}_{2} \mathrm{O}$.

To confirm adequacy of treatment of sleep and breathing in auto mode the subjects also slept in the laboratory with polysomnographic recording on days 0,60 , and $120 .{ }^{19}$ The subjects were fully responsible for managing their own mask and machine on these nights. There was an excellent improvement in AHI (diagnostic night 53 (4.4) events/h, auto 3.5 (2.5) events/h, $\mathrm{p}<0.0001)$, microarousal index $\begin{array}{lll}\text { (diagnostic } 47.1 & \text { (3.5) events/h, auto } 7.7\end{array}$ (2.0) events/h, p<0.001), REM and slow wave sleep as a percentage of time in bed (diagnostic $10.3(1.7) \%$, auto 17.8 (1)\%, p<0.01, and diagnostic 9.1 (2.7)\%, auto 17.6 (1.6)\%, $\mathrm{p}<0.01$, respectively).

The AutoSet device automatically scores apnoeas and hypopnoeas. The AHI scored by the device was $3.7(0.3)$ events/h during two months in auto mode (essentially identical to the value determined at polysomnography) and 4.0 (0.3) during two months at manually determined fixed pressure (NS). The AHI scored with the AutoSet device has been well validated elsewhere in diagnostic mode..$^{22-24}$

To assess effectiveness at treating sleep apnoea syndrome, the MSLT (Multiple Sleep Latency Test) and MWT (Maintenance Wakefulness Test) were measured prior to commencement and at the end of each two month period and analysed using two way repeated measures ANOVA. ${ }^{19}$ Subjects were not particularly sleepy prior to CPAP. The MSLT was 13 (1) $\mathrm{min}$ before treatment, 11 (1) $\mathrm{min}$ at two months, and 15 (1.5) min at four months. There was no significant change from before treatment to that at two or four months, nor was there a significant difference between auto and fixed modes (auto 13 (1) min, fixed 13 (1) min). Conversely, MWT showed a small progressive improvement with time (25 (3) min before treatment, 32 (3) $\mathrm{min}$ at two months $(p=0.03), 34(2) \mathrm{min}$ at four months $(p=0.01))$. Again, there was no difference between auto and fixed modes (auto 32 (2) min, fixed 34 (2) min, $p=0.06$ ). Thus there was a small and equal improvement in MWT with both devices.

\section{Who might benefit?}

Subjects who always require only a very low pressure (for example, $4 \mathrm{~cm} \mathrm{H}_{2} \mathrm{O}$ ) to treat all events on all occasions cannot in principle benefit from an auto-adjusting device. Conversely, subjects who require very high pressures would almost certainly benefit if the peak pressure is required for short periods only. Since the night-to-night within-subject variability in titration pressure is of the order of 


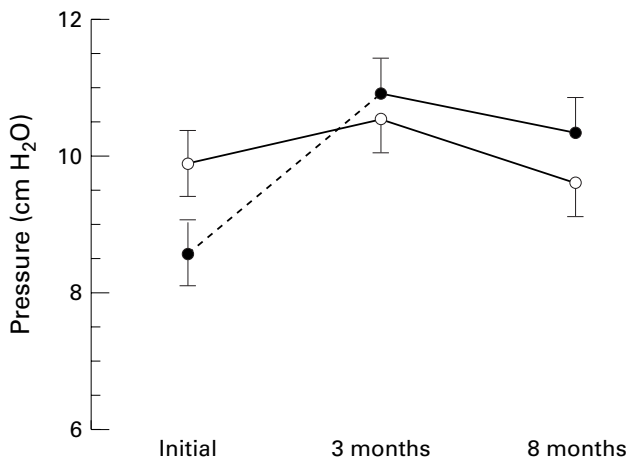

Figure 3 Titration pressure on initial titration, at three months, and at eight months. Open circles = AutoSet titration, 95th centile pressure during periods with leaking of $<0.4 \mathrm{l} / \mathrm{s}$. Closed circles = manual titration; for initial visit obstructive apnoeas and hypopnoeas were eliminated and on subsequent titration snoring was also eliminated. The mean AutoSet titration pressure did not change with time. As expected, the manual titration pressure on the first visit was lower than either the AutoSet pressure $(p<0.001)$ or the subsequent manual titration pressures $(p<0.001)$. Error bars are within-subject $95 \%$ confidence intervals.

$1 \mathrm{~cm} \mathrm{H}_{2} \mathrm{O}$ standard deviation, these two extremes are identifiable at the time of the initial titration. It is not known to what extent subjects who require intermediate pressures might benefit. A very rough estimate might be gained from the observation that, in our series of 1000 patients, $12 \%$ required a peak pressure of $12 \mathrm{~cm} \mathrm{H}_{2} \mathrm{O}$ or above whereas $21 \%$ of subjects required a pressure of $7 \mathrm{~cm} \mathrm{H}_{2} \mathrm{O}$ or less.

\section{Stability of titration pressure over eight months}

Since titration pressure for subsequent fixed pressure therapy is generally measured on a single night only, it is of great clinical relevance to know whether the titration pressure is stable over time. Series and colleagues ${ }^{25}$ demonstrated a gradual decline in titration pressure of the order of $20 \%$ over nine months. Conversely, Konermann et $a l^{26}$ found a slight increase in titration pressure with the passage of time. Neither of these studies explicitly attempted to eliminate silent inspiratory airflow limitation.

To address this question the 20 subjects titrated using AutoSet Clinical were retitrated after three and eight months. ${ }^{18}$ AutoSet titra-

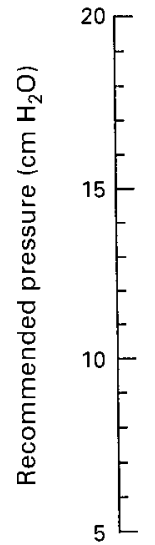

Control
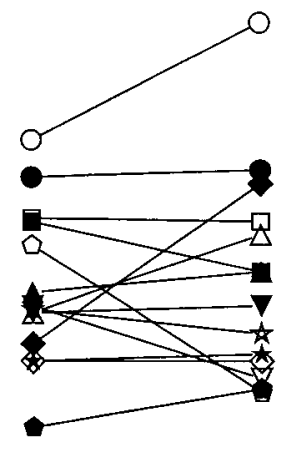

Alcohol

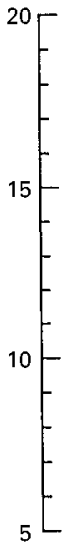

Control

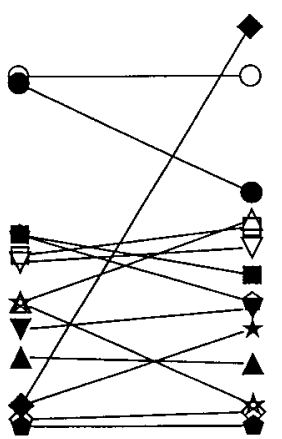

Alcohol
Figure 4 AutoSet recommended fixed pressure for nasal continuous airway pressure (CPAP) for the first two hours and for the full night without (control) and with alcohol. tion pressure was $9.9(0.4) \mathrm{cm} \mathrm{H}_{2} \mathrm{O}$ initially, $10.6(0.4) \mathrm{cm} \mathrm{H}_{2} \mathrm{O}$ at three months, and 9.7 (0.5) $\mathrm{cm} \mathrm{H}_{2} \mathrm{O}$ at eight months (fig 3). There was no significant change with time. In a separate study $^{19}$ the 10 subjects using AutoSet Portable were retitrated at two and four months. No significant change was seen in the AutoSet titration pressure $\left(10.7(0.6) \mathrm{cm} \mathrm{H}_{2} \mathrm{O}\right.$ before treatment, $9.2(0.7) \mathrm{cm} \mathrm{H}_{2} \mathrm{O}$ at two months, and $11.1(0.6) \mathrm{cm} \mathrm{H}_{2} \mathrm{O}$ at four months), although there was a small transient decrease in the median pressure. Taking these two studies together, there is no important or sustained systematic change in the pressure required to eliminate inspiratory airflow limitation at two, three, four, or eight months.

\section{Stability of titration pressure and} breathing with alcohol

We argued that, since consumption of alcoholic beverages worsens snoring, ${ }^{15}$ a social amount of pure alcohol might worsen untreated OSA and, by further relaxing the upper airway, increase the titration pressure. To study the stability of titration pressure further 14 men with untreated uncomplicated OSA were studied with and without $1.5 \mathrm{ml} / \mathrm{kg} 40 \%$ vodka (blood alcohol $0.45 \mathrm{mg} / \mathrm{ml}$ ). ${ }^{14}$ Surprisingly, without CPAP there was no significant or important change in AHI, arousal index, sleep architecture, or saturation with the exception of one subject who showed prolonged periods of hypoventilation without much desaturation after alcohol. There was a slight but non-significant decrease in the percentage of REM with alcohol on the non-CPAP night (11 (2)\% versus 8 (1) \%). The AutoSet titration pressure was 11.9 (0.9) $\mathrm{cm} \mathrm{H}_{2} \mathrm{O}$ without alcohol and $12.5 \mathrm{~cm} \mathrm{H}_{2} \mathrm{O}$ with alcohol (NS, fig 4). Again there were no important or significant changes in sleep or breathing with alcohol during CPAP therapy. These results are consistent with the notion that, unlike snorers, in subjects with OSA the upper airway is already completely floppy so that alcohol cannot make matters worse. Since the existing CPAP pressure adequately maintains airway patency, a modest dose of pure alcohol therefore has no important consequences for sleep and breathing during CPAP therapy. ${ }^{14}{ }^{27}$ We hasten to point out that these results cannot be extrapolated to alcoholic beverages containing vasodilator substances (histamine, tyramine) which may lead to a large increase in nasal airway resistance, nor to higher doses of alcohol which may lead to a reduction in arousal response, particularly in subjects with overlap syndrome. ${ }^{15}$

Unattended titration: risks and benefits It is clear from the previous studies and others $^{28-30}$ that, in suitable patients with uncomplicated OSA, auto-titration does not require polysomnography and can, in some cases, be performed unattended. This has the potential for great savings in labour and time. However, there are some risks to this approach that must be managed. Subjects with predominantly central sleep apnoea - for example, after brainstem 
stroke or cardiac failure - are not suitable for auto-titration. Those with respiratory insufficiency are at risk of prolonged hypoventilation $^{33} 34$ and may need oxygen and/or ventilatory assistance, and those with hypovolaemia are at risk of a reduction in cardiac output. ${ }^{31}{ }^{32}$ Subjects with uncontrolled asthma, epilepsy, angina, fluid and electrolyte disturbances, and psychiatric illness need special care. In addition, those with other coexisting diseases such as nocturnal myoclonus, epilepsy, and other parasomnias may be missed. Perhaps the most important role of the titration night is to provide patient education and support. Finally, as mentioned above, severe mask leakage can interfere with the supervised auto-titration process in about $4 \%$ of cases and therefore in the unattended case a record of mask leakage must be available.

Unattended titration or titration without polysomnography is therefore appropriate only if (1) severely ill patients with cardiac failure, respiratory failure, etc can be safely eliminated, (2) mechanisms including follow up are put in place to ensure that other coexisting sleep disorders are not missed, and (3) there is an excellent patient education and support system in place. If these provisions are formally met the risk of delaying the institution of nasal CPAP therapy, or of being unable to provide it at all, outweighs the risks discussed above.

\section{Conclusions}

The CPAP pressure required to prevent silent inspiratory airflow limitation does not vary systematically with time over the first eight months of treatment, and this suggests that it is not necessary to lengthen waiting lists by regularly retitrating asymptomatic patients. Long term home therapy with an autoadjusting device that eliminates silent inspiratory airflow limitation can produce a reduction of up to $37 \%$ in mean pressure delivery with no reduction in effectiveness. Modest doses of pure alcohol (approximately equivalent to half a bottle of wine) have no important effect on titration pressure or on sleep architecture during CPAP therapy for uncomplicated OSA. However, it is unlikely that these results extrapolate to other alcoholic beverages, higher doses, or to subjects with overlap syndrome.

Auto-titration to eliminate silent inspiratory airflow limitation offers a satisfactory method for determining a single pressure suitable for subsequent fixed pressure nasal CPAP home therapy in patients with simple uncomplicated OSA. Unattended titration becomes practicable. However, it is crucial that there is no possibility of coincident severe medical disease, particularly severe cardiac failure or respiratory insufficiency. Auto-titration without polysomnography also becomes practicable, but a mechanism must exist for identifying other sleep disorders such as narcolepsy and myoclonus. Finally, a meticulous education, mask fitting, and follow up service must be provided. These caveats must be weighed against the cost of delaying initiation of CPAP therapy, or of being unable to provide it at all, and this will depend on the regional health care facilities.

1 Sullivan CE, Issa FG, Berthon-Jones M, et al. Reversal of obstructive sleep apnea by continuous positive airway pressure applied through the nares. Lancet 1981;i:862-5.

2 Sullivan CE, Grunstein R. Continuous positive airway pressure in sleep disordered breathing. In: Kryger M, Roth Philadelphia: WB Saunders, 1994: 694-705.

3 Condos R, Norman RG, Krishnasamy I, et al. Flow limitation as a noninvasive assessment of residual upper-airway Cositive airway pressure therapy of obstructive sleep apnea. Am f Respir Crit Care Med 1994;150:475-80

4 Montserrat JM, Ballester E, Olivi H, et al. Time-course of stepwise CPAP titration. Am 7 Respir Crit Care Med 1995; 152:1854-9.

5 George CF, Millar TW, Kryger MH. Sleep apnea and body position during sleep. Sleep 1988;11:90-9.

6 McNicholas WT, Tarlo S, Cole P, et al. Obstructive apneas during sleep in patients with seasonal allergic rhinitis. $\mathrm{Am}$ Rev Respir Dis 1982;126:625-8.

7 Hoffstein V, Viner S, Mateika S, et al. Treatment of obstructive sleep apnea with nasal continuous positive airway pressure. Patient compliance, perception of benefits, and side effects. Am Rev Respir Dis 1992;145: 841-5.

8 Engleman HM, Martin SE, Douglas NJ. Compliance with CPAP therapy with the sleep apnoea/hypopnea syndrome. Thorax 1994;49:263-6.

9 Krieger J. Long-term compliance with nasal continuous positive airway pressure (CPAP) in obstructive sleep apnea patients and nonapneic snorers. Sleep 1992; Suppl 6:42-6.

10 Reeves-Hoché MK, Meck R, Zwillich CW. Nasal CPAP: an objective evaluation of patient compliance. Am F Respir Crit Care Med 1994;149:149-54.

11 Nino-Murcia G, Crowe-McCann C, Bliwise DL, et al. Compliance and side effects in sleep apnea patients treated with nasal continuous positive airway pressure. West $\mathcal{F}$ Med 1989;150:165-9.

12 Berthon-Jones M, Lawrence S, Sullivan CE, et al. Nasal continuous positive airway pressure treatment. Current realities and future. Sleep 1996;19(Suppl):S131-5.

13 American Thoracic Society. Indications and standards for use of nasal continuous positive airway pressure (CPAP) in sleep apnea syndromes. Am $\mathcal{f}$ Respir Crit Care Med 1994;150:1738-45.

14 Teschler H, Berthon-Jones M, Wessendorf T, et al. Influence of moderate alcohol consumption on obstructive sleep of moderate alcohol consumption on obstructive sleep Eur Respir 7 1996;9:2371-7.

15 Issa FG, Sullivan CE. Alcohol, snoring and sleep apnea. $\mathcal{F}$ Neurol Neurosurg Psychiatry 1982;45:353-9.

16 Berthon-Jones M. Feasibility of a self-setting CPAP machine. Sleep 1993;16:120-3.

17 Teschler H, Berthon-Jones $\mathrm{M}$, Thompson $\mathrm{AB}$, et al. Automated continuous positive airway pressure titration for obstructive sleep apnea syndrome. Am $\mathcal{F}$ Respir Crit Care Med 1996;154:734-40.

18 Teschler H, Farhat AA, Exner V, et al. AutoSet nasal CPAP titration: constancy of pressure, compliance and effectiveness at 8 months follow-up. Eur Respir f 1997,10:2073-8.

19 Teschler H, Berthon-Jones M, Wessendorf T, et al. Variability of CPAP pressure during long-term home autotitration
in obstructive sleep apnea. Am $\mathscr{f}$ Respir Crit Care Med 1996;153:A773.

20 Mathur R, Douglas NJ. Frequency of EEG arousals from nocturnal sleep in normal subjects. Sleep 1995;18:330-3.

21 Pevernagie DA, Shepard JW. Relations between sleep stage, posture and effective nasal CPAP levels in OSA. Sleep 1992;15:162-7.

22 Bradley P, Mortimore IL, Douglas NJ. Comparison of polysomnography with ResCare AutoSet in the diagnosis of the sleep apnoea/hypopnoea syndrome. Thorax 1995;50: 1201-3

23 Gugger M. Comparison of ResMed AutoSet (version 3.03) with polysomnography in the diagnosis of the sleep
apnoea/hypopnoea syndrome. Eur Respir $f$ 1997;10:567apno

24 Kiely JL, Delahunty C, Mattews S, et al. Comparison of a limited computerised diagnostic system (ResCare Autoset ${ }^{\mathrm{TM}}$ ) with polysomnography in the diagnosis of obstructive sleep apnoea syndrome. Eur Respir f 1996;9:2360-4.

25 Series F, Marc I, Cormier Y, et al.. Required levels of nasal continuous positive airway pressure during treatment of obstructive sleep apnoea. Eur Respir f 1994;7:1776-81.

26 Konermann M, Sanner B, Burmann-Urbanek C, et al. Konstanz der nCPAP-Druckwerte in der Langzeitüberwachung von Patienten mit obstruktiver Schlafapnoe. Dtsch Med Wschr 1995;120:125-9.

27 Berry RB, Desa MM, Light RW. Effect of ethanol on the efficacy of nasal continuous positive airway pressure as a treatment for obstructive sleep apnea. Chest 1991;99:33943.

28 Lofaso F, Lorino AM, Duizabo D, et al. Evaluation of an auto-nCPAP device based on snoring detection. Eur Respir f 1996;9:1795-800.

29 Sharma S, Wali S, Pouliot Z, et al. Treatment of obstructive sleep apnea with a self-titrating continuous positive airway pressure (CPAP) system. Sleep 1996;19:497-501. 
30 Scharf MB, Brannen DE, McDannold MD, et al. Computerized adjustable versus fixed nCPAP treatment of terized adjustable versus fixed nCPAP t
obstructive sleep apnea. Sleep 1996;19:491-6.

31 Genovese J, Moskowitz M, Tarasiuk A, et al. Effects of continuous positive airway pressure on cardiac output in normal and hypervolemic unanesthetized pigs. Am $\mathcal{F}$ Respir Crit Care Med 1994;150:752-8.

32 Naughton MT, Rahman A, Hara K, et al. Effect of continuous positive airway pressure on intrathoracic and left ventricular transmural pressures in patients with congestive heart failure. Circulation 1995;91:1725-31.

33 Restrick LJ, Fox NC, Braid G, et al. Comparison of nasal pressure support ventilation with nasal intermittent positive pressure ventilation in patients with nocturnal hypoventilation. Eur Respir f 1993;6:364-70.

34 Piper AJ, Sullivan CE. Effects of short-term NIPPV in the treatment of patients with severe obstructive sleep apnea and hypercapnia. Chest 1994;105:434-40. 